\title{
Inhibition of Carrageenan-Induced Cutaneous Inflammation by PPAR Agonists Is Dependent on Hepatocyte-Specific Retinoid X Receptor Alpha
}

\author{
Yu-Jui Yvonne Wan' ${ }^{1}$ and Mostafa Z. Badr² \\ ${ }^{1}$ Department of Pharmacology, Toxicology \& Therapeutics, The University of Kansas Medical Center, Kansas City, KS 66160, USA \\ ${ }^{2}$ Division of Pharmacology, School of Pharmacy, University of Missouri-Kansas City, Kansas City, MO 64108, USA
}

Received 30 January 2006; Revised 20 April 2006; Accepted 21 April 2006

It has been proposed that PPAR-dependent, accelerated catabolism of proinflammatory mediators may contribute to the fast resolution of inflammation. Because retinoid X receptors are obligate heterodimer partners of PPARs, we investigated the impact of deleting hepatocyte-specific RXR $\alpha$ on the antiedema effect of PPAR agonists. In wild-type mice (WT), pretreatment with the $\operatorname{PPAR} \alpha$ agonist perfluorooctanoic acid diminished carrageenan-induced paw edema by $66 \pm 10 \%$. This effect was essentially absent $(13 \pm 8 \%)$ in hepatocyte-specific RXR $\alpha$-deficient mice. Similarly, pretreatment of WT mice with the PPAR $\delta$ agonist L-783483 or the PPAR $\gamma$ agonist L- 805645 caused $54 \pm 1 \%$ and $38 \pm 8 \%$ reduction in carrageenan-induced paw edema, respectively. These effects were also significantly diminished or absent in hepatocyte-specific $\operatorname{RXR} \alpha$-deficient mice. In contrast, aspirin reduced carrageenaninduced paw edema equally in WT and hepatocyte-specific RXR $\alpha$-deficient mice. The identification of RXR $\alpha$ as an important factor involved in the antiedema effect produced by agonists of the three PPAR subtypes is a significant achievement towards the goal of designing novel, effective anti-inflammatory drugs.

Copyright (c) 2006 Y.-J. Y. Wan and M. Z. Badr. This is an open access article distributed under the Creative Commons Attribution License, which permits unrestricted use, distribution, and reproduction in any medium, provided the original work is properly cited.

\section{INTRODUCTION}

It has been reported by us [1-3], as well as by others [4-6] that agonists of the peroxisome proliferator-activated receptors (PPARs) diminish inflammatory responses. In attempting to delineate mechanisms involved in this effect, it was proposed among various other postulates that termination of the biological activity of proinflammatory mediators might occur in the liver via PPAR-dependent catabolic pathways [4]. These pathways are known to be augmented following exposure to PPAR agonists, particularly those which activate $\operatorname{PPAR} \alpha[4]$.

Retinoid X receptor alpha $(\mathrm{RXR} \alpha)$ is reported to play a central role in mediating PPAR-induced effects [7-9], and the expression of both PPARs and RXRs decreases in tissues, including the liver of animal models of inflammation [10]. Therefore, we hypothesized that the absence of hepatocytespecific RXR $\alpha$ shall interfere with the ability of PPAR agonists to control inflammation. Using the intraplantar injection of carrageenan as a well-established in vivo model of inflammation, the present experiments were designed to evaluate the anti-inflammatory effect of subtype-selective PPAR ligands in hepatocyte-specific RXR $\alpha$-deficient mice. Results show that hepatocytic RXR $\alpha$ plays an important role in mediating the PPAR-induced amelioration of cutaneous inflammation. We postulate that the hepatocyte-specific RXR $\alpha$ is involved in enhancing the metabolic removal of proinflammatory mediators and/or increasing the production of antiinflammatory mediators in the liver.

The identification of a specific receptor subtype $(\mathrm{RXR} \alpha)$ in a specific cell population (hepatocytes) may prove instrumental in the pursuit to fully elucidate mechanisms involved in the antiinflammatory effect of PPAR agonists, as well as invaluable to the effort of developing novel effective antiinflammatory drugs.

\section{MATERIALS AND METHODS}

\section{Animals and materials}

Male hepatocyte-specific RXR $\alpha$-deficient mice were produced as reported previously [9]. Animals were cared for in accordance to the guidelines set forth by the National Institutes of Health regarding the proper treatment and use 


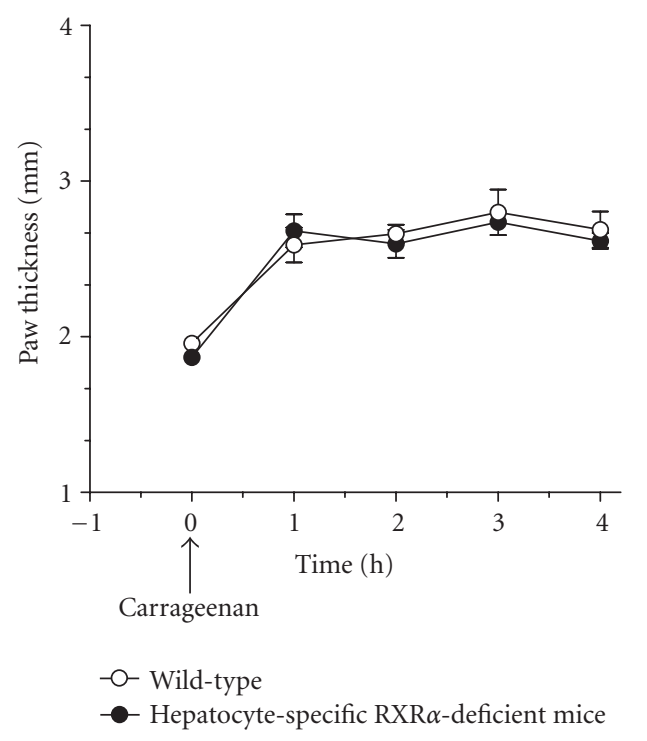

FIgURE 1: Carrageenan-induced paw edema in hepatocyte-specific $R X R \alpha$-deficient mice. Wild-type and hepatocyte-specific $\operatorname{RXR} \alpha$ deficient mice were treated with $30 \mu \mathrm{L}$ of $1 \%$ carrageenan in normal saline subcutaneously into the midplantar region of the right hindpaw. Carrageenan-induced edema, reflected as an increase in dorsal-to-ventral paw thickness, was measured with a microcaliper. Values represent mean \pm SEM. $n=8$ mice per group.

of laboratory animals. All experiments were approved by the University of Missouri-Kansas City Institutional Animal Care and Use Committee.

Carrageenan (type IV, lambda) was obtained from Fluka (Milwaukee, WI), while aspirin and perfluorooctanoic acid were from Sigma Aldrich (St Louis, MO). The PPAR $y$ agonist L-805645 and PPAR $\delta$ agonist L-738483 were provided by Merck (Rahway, NJ).

\section{Animal treatment}

Tested compounds $(200 \mu \mathrm{L}$ in normal saline at a dose of $100 \mathrm{mg} / \mathrm{kg}$ ), or the saline vehicle, was administered intraperitoneally to wild-type and hepatocyte-specific RXR $\alpha$ deficient mice. Since we previously observed that PPAR agonists equally diminished inflammation when given $30 \mathrm{~min}$ utes prior to, or 90 minutes after the induction of paw edema [1], we limited the present study to the 30 minute precarrageenan injection of PPAR agonists. Carrageenan $(30 \mu \mathrm{L}$ of $1 \%$ in normal saline), or an equivalent volume of saline, was subcutaneously injected into the midplantar region of the right hindpaw. Carrageenan-induced edema, reflected as an increase in dorsal-to-ventral paw thickness, was measured with a microcaliper (Mitutoyo Corp; Kanagawa, Japan). The average of 3 measurements at each time-point was calculated.

\section{Data analysis and statistics}

Carrageenan-evoked edema responses were analyzed by Student's $t$ test (Figures 1 and 6), or ANOVA (Figures 2-5). $P<.05$ was considered significant.

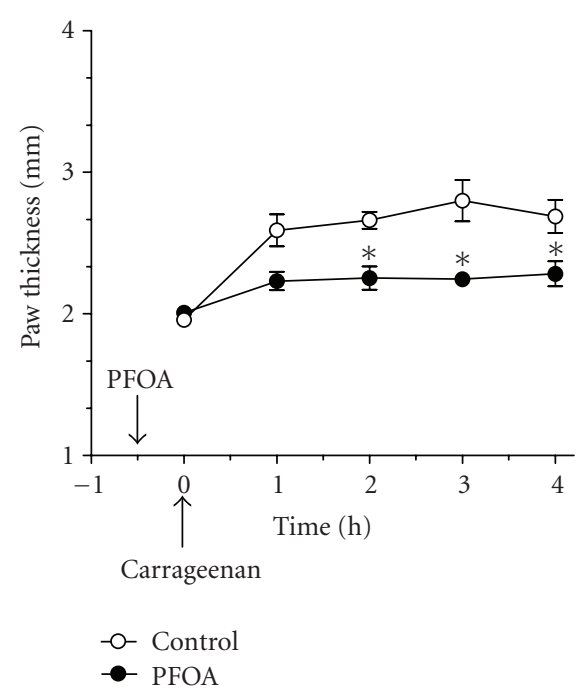

(a)

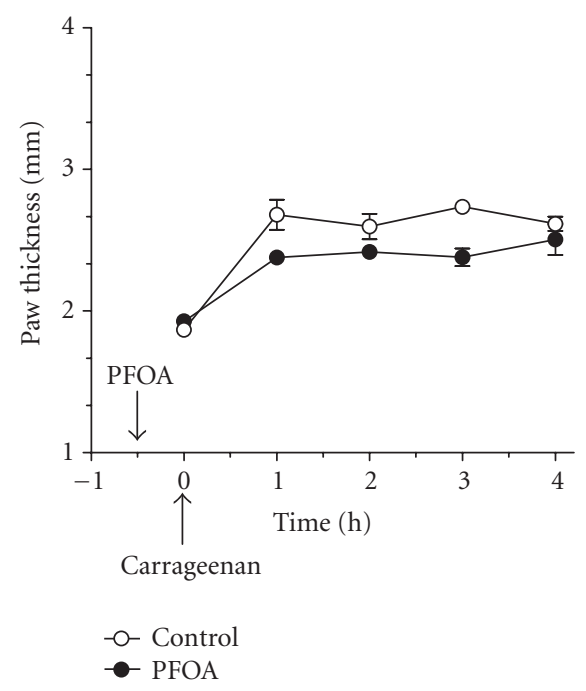

(b)

FIGURE 2: Effect of the PPAR $\alpha$ agonist perfluorooctanoic acid (PFOA) on the temporal profile of carrageenan-induced paw edema in wildtype and hepatocyte-specific RXR $\alpha$-deficient mice. Wild-type (A) and hepatocyte-specific RXR $\alpha$-deficient mice (B) were treated intraperitoneally with $(100 \mathrm{mg} / \mathrm{kg})$ of PFOA, 30 minutes before induction of inflammation. As indicated by the arrow, carrageenan (1\%, intraplantar) was injected at $t=0$. Carrageenan-induced edema is reflected by an increase in paw thickness. Values represent mean \pm SEM. $n=4$ mice per group. ${ }^{*} P<.05$ versus corresponding wildtype point.

\section{RESULTS}

\section{Influence of hepatocyte-specific $R X R \alpha$ on carrageenan-induced paw edema}

As illustrated in Figure 1, intraplantar injection of carrageenan in wild-type mice increased paw thickness, with a peak at approximately $1 \mathrm{hr}$ post-injection. The maximal 


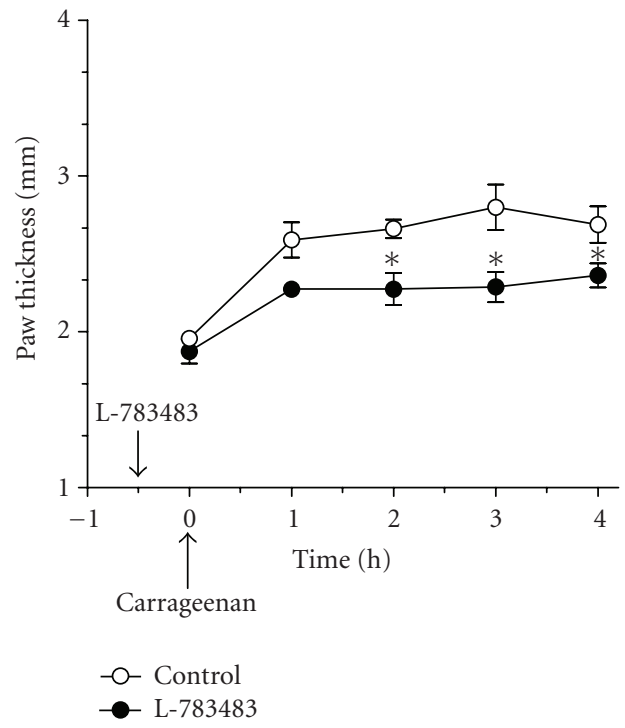

(a)

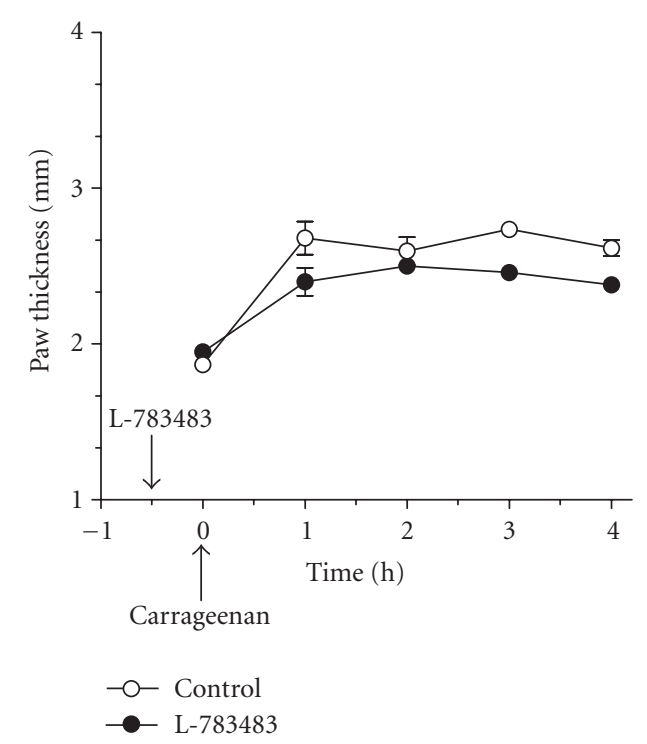

(b)

FIGURe 3: Antiedema effect of the PPARS agonist L-738483 on carrageenan-induced paw edema in wild-type and hepatocyte-specific RXR $\alpha$ deficient mice. Wild-type (a) and hepatocyte-specific RXR $\alpha$-deficient mice (b) were treated intraperitoneally with (100 mg/kg) of L-738484, 30 minutes before induction of inflammation. As indicated by the arrow, carrageenan (1\%, intraplantar) was injected at $t=0$. Carrageenaninduced edema is reflected by an increase in paw thickness. Values represent mean \pm SEM. $n=3-5$ mice per group. ${ }^{*} P<.05$ versus corresponding wild-type point.

increase in paw thickness was 35\% over basal values, and lasted through the $4 \mathrm{hr}$ duration of the experiment. Mice lacking hepatocyte-specific $\operatorname{RXR} \alpha$ also showed a comparable increase and trend in paw thickness in response to intraplantar carrageenan injection (Figure 1).

\section{Antiedema effect of PPAR agonists in hepatocyte-specific $R X R \alpha$-deficient mice}

In wild-type mice, pretreatment with $100 \mathrm{mg} / \mathrm{kg}$ of the $\operatorname{PPAR} \alpha$ agonist perfluorooctanoic acid (PFOA) diminished carrageenan-induced paw edema by $66 \pm 10 \% 2-4 \mathrm{~h}$ following carrageenan injection (Figures 2(a) and 6). This effect was essentially absent $(13 \pm 8 \%)$ in hepatocyte-specific RXR $\alpha$-deficient mice (Figures 2(b) and 6). Similarly, pretreatment of wild-type mice with similar doses of either of the PPAR $\delta$ agonist L-783483, or the PPAR $\gamma$ agonist L-805645 caused $54 \pm 1 \%$ and $38 \pm 8 \%$ reduction in carrageenaninduced paw edema, respectively (Figures 3(a), 4(a), and 6). These effects were significantly lower $(30 \pm 6 \%)$ or absent $(8 \pm 5 \%)$ in hepatocyte-specific $\mathrm{RXR} \alpha$ deficient mice, respectively (Figures 3(b), 4(b), and 6). Conversely, aspirin which is a known inhibitor of the cyclooxygenase enzyme, reduced carrageenan-induced paw edema equally in wild-type and hepatocyte-specific RXR $\alpha$-deficient mice (Figures 5 and 6). The reduction in paw edema was $51 \pm 12 \%$ and $51 \pm 3 \% \mathrm{x}$ in these two groups of mice, respectively (Figure 6).

\section{DISCUSSION}

Retinoid X receptors (RXR) play a central role as obligate heterodimer partners for numerous nuclear receptors, including PPARs [7]; thereby serving as master regulators of crucial pathways [7]. The RXR/PPAR heterodimer is activated by agonists of either RXR or PPAR, leading to the activation of specific pathways [8], with the combination of RXR and PPAR agonists causing a greater effect than agonists of either receptor alone [8]. Genetic deletion of hepatocytespecific RXR $\alpha$ drastically, albeit not completely, interfered with PPAR-mediated pathways $[9,10]$. In light of these facts, this study was pursued to take advantage of the availability of mice lacking hepatocyte $\operatorname{RXR} \alpha$ to investigate potential role played by the liver in the antiedema effect ascribed to PPAR agonists.

Our data clearly show that the absence of hepatocytespecific $\operatorname{RXR} \alpha$ significantly diminished the ability of agonists of $\operatorname{PPAR} \alpha, \operatorname{PPAR} \delta$, and PPAR $\gamma$ to exert antiedema effect in vivo, while exhibiting no effect on aspirin-induced antiedema (Figures 2-6). A previous study concluded that activation of PPAR $\alpha$ hastened the catabolic termination of the inflammatory response to leukotriene $\mathrm{B}_{4}$ [4]. In support of this conclusion, preliminary experiments by the same authors showed diminished plasma clearance of leukotriene $\mathrm{B}_{4}$ in $\operatorname{PPAR} \alpha$-deficient mice, as compared to wild-type mice [4]. It should be noted however that in contrast to the beneficial effect of PPAR $\alpha$ agonists in controlling inflammatory processes, published reports present evidence for a proinflammatory response to these agonists; an effect that is explained by potential differences in cell- and/or tissue-specific susceptibility [11].

PPAR $y$ agonists have been shown to interfere with numerous pathways involved in the inflammatory process, in the course of exerting their reported anti-inflammatory activity [11]. However, whether agonists of PPAR $\gamma$ and/or 


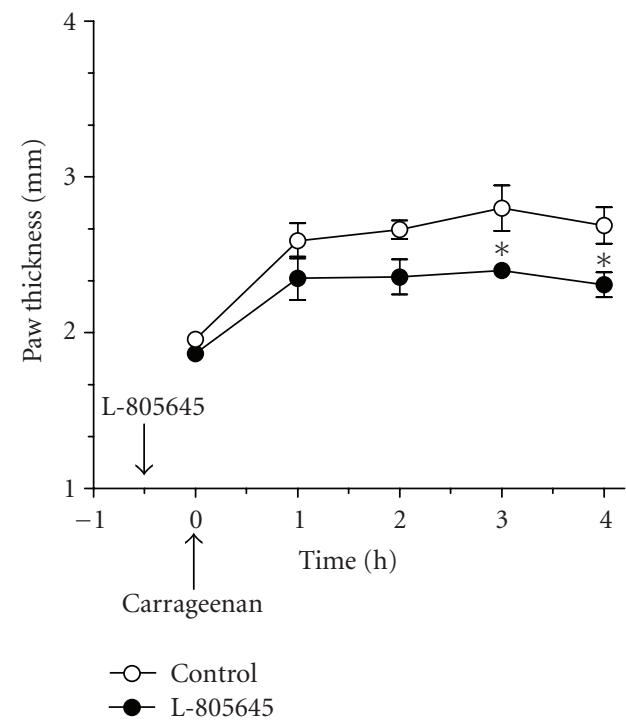

(a)

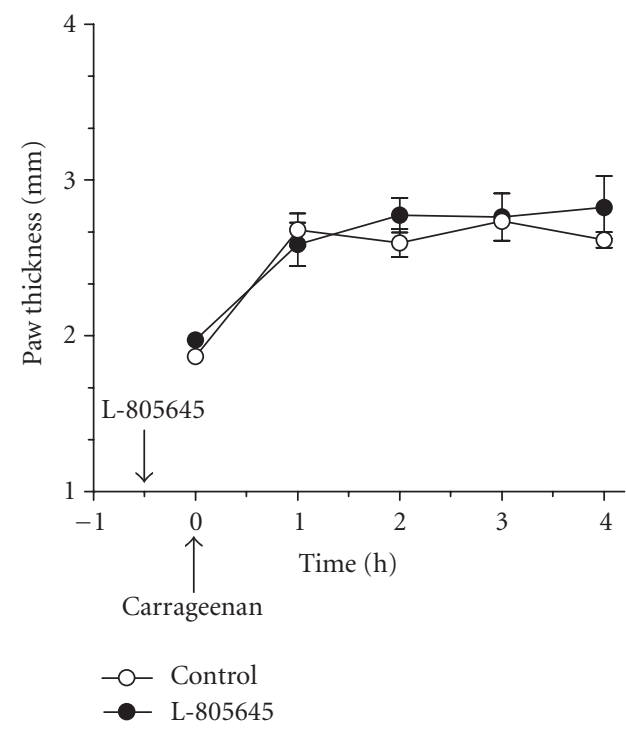

(b)

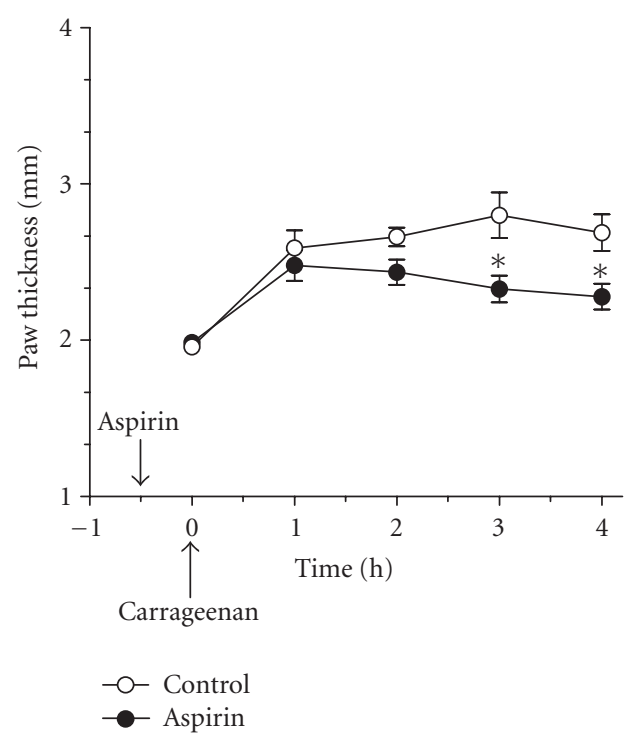

(a)

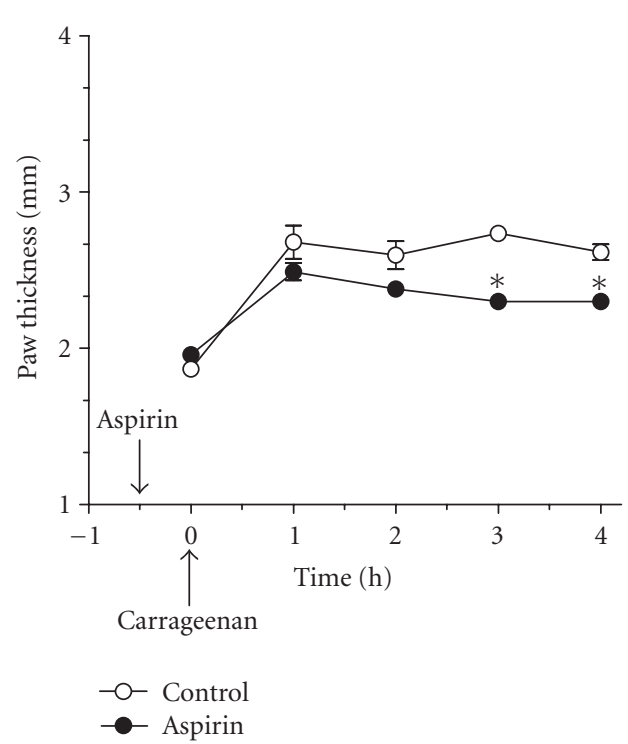

(b)
FIGURE 4: Effect of the PPARy agonist L-805645 on the profile of carrageenan-induced paw edema in wild-type and hepatocyte-specific $R X R \alpha$-deficient mice. Wild-type (a) and hepatocyte-specific $\operatorname{RXR} \alpha$ deficient mice (b) were treated intraperitoneally with $(100 \mathrm{mg} / \mathrm{kg})$ of L-805645, 30 minutes before induction of inflammation. As indicated by the arrow, carrageenan ( $1 \%$, intraplantar) was injected at $t=0$. Carrageenan-induced edema is reflected by an increase in paw thickness. Values represent mean \pm SEM. $n=4-6$ mice per group. ${ }^{*} P<.05$ versus corresponding wild-type point.

$\operatorname{PPAR} \delta$ recruit the hepatic metabolic machinery to control inflammation is not reported in the literature. Thus, this is the first report, to our knowledge, that presents an evidence for a unifying mechanism involving the liver, explaining the anti-inflammatory effect of agonists of the three known PPAR subtypes.
FIGURE 5: Effect of aspirin on carrageenan-induced paw edema in wild-type and hepatocyte-specific RXR $\alpha$-deficient mice. Wild-type (a) and hepatocyte-specific RXR $\alpha$-deficient mice (b) were treated intraperitoneally with $(50 \mathrm{mg} / \mathrm{kg})$ of aspirin, 30 minutes before induction of inflammation. As indicated by the arrow, carrageenan (1\%, intraplantar) was injected at $t=0$. Carrageenan-induced edema is reflected by an increase in paw thickness. Values represent mean \pm SEM. $n=3-5$ mice per group. ${ }^{*} P<.05$ versus corresponding wild-type point.

The specific requirement for RXR $\alpha$ by all PPAR subtypes, observed in this study, may be explained by the fact that this receptor is a heterodimer partner of the three PPAR subtypes. The absence of RXR $\alpha$ is consequently expected to hinder the activation of pathways controlled by agonists selective to any of the various PPAR subtypes. In order to 


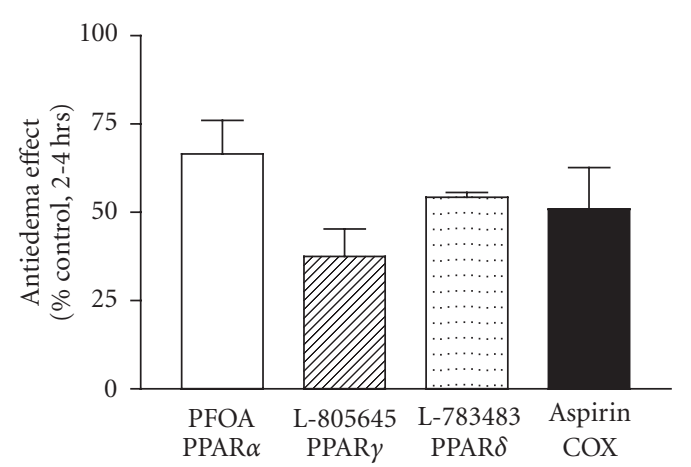

(a)

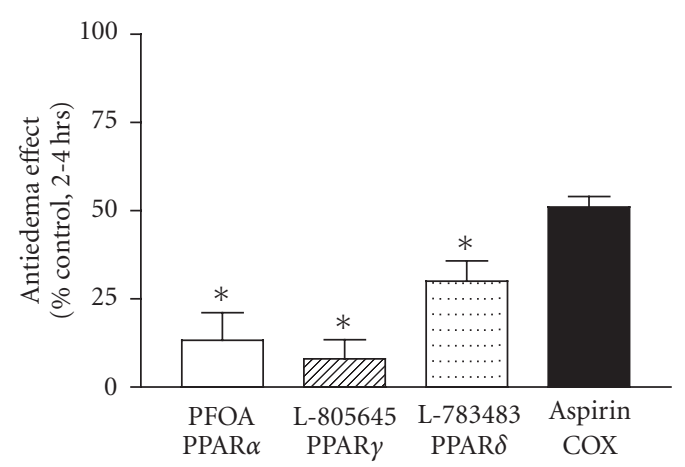

(b)

FIgure 6: Percent inhibition of paw edema by various PPAR agonists and aspirin in wild-type (a) and hepatocyte-specific RXR $\alpha$-deficient (b) mice. Data shown in Figures 2-5 above are expressed as the percentage change in paw edema relative to control group 2-4h after carrageean injection. Values represent mean \pm SEM. $N=3-6$ mice per group. ${ }^{*} P<.05$ versus corresponding wild-type group.

explain the residual anti-inflammatory effect of PPAR agonists observed in hepatocyte-specific RXR $\alpha$-deficient mice, we propose the following. (1) It is noteworthy that these agonists have been shown to produce effects that are not PPAR-dependent [12-16]. This is an unlikely explanation however in light of the fact that preliminary experiments in our laboratories reveal that PPAR $\alpha$ plays a significant role in mediating the anti-inflammatory effect of its agonists (not shown). (2) Another possibility that may explain the residual anti-inflammatory effect of PPAR agonists observed in hepatocyte-specific $\operatorname{RXR} \alpha$-deficient mice takes into considerations the fact that these mice retain the ability to express $\operatorname{RXR} \beta$ and RXR $\gamma$ in hepatocytes $[9,10]$. Both of these receptor subtypes may act as heterodimer partners of PPARs in the absence of RXR $\alpha[9,10]$. (3) Since our animal model lacks $\operatorname{RXR} \alpha$ exclusively in hepatocytes [10], $\operatorname{RXR} \alpha$ present in liver cell types other than hepatocytes may contribute to the partial anti-inflammatory effect of PPAR agonists observed in these mice. (4) Lastly, whether there are PPAR-mediated effects that are not fully dependent on the heterodimerization of these receptors with RXRs is an interesting postulate that deserves evaluation.
In conclusion, data presented here show that hepatic events involving $\mathrm{RXR} \alpha$ are crucial to the antiedema effect of PPAR agonists. These effects may include acceleration of the metabolic removal of proinflammatory mediators and/or enhanced production of antiinflammatory mediators in the liver. Identifying hepatocyte-specific RXR $\alpha$ as a crucial link in the mechanism by which PPAR agonists produce antiinflammatory effect is indeed a significant first step towards fully defining molecular events involved in this action, as well as designing novel, effective anti-inflammatory drugs.

\section{ACKNOWLEDGMENT}

This paper was partially supported by National Institutes of Health Grants CA53596 and AA14147 to YW.

\section{REFERENCES}

[1] Taylor BK, Kriedt C, Nagalingam S, Dadia N, Badr MZ. Central administration of perfluorooctanoic acid inhibits cutaneous inflammation. Inflammation Research. 2005;54(6):235242.

[2] Youssef J, Badr MZ. Role of peroxisome proliferator-activated receptors in inflammation control. Journal of Biomedicine and Biotechnology. 2004;2004(3):156-166.

[3] Taylor BK, Dadia N, Yang CB, Krishnan S, Badr MZ. Peroxisome proliferator-activated receptor agonists inhibit inflammatory edema and hyperalgesia. Inflammation. 2002;26(3): 121-127.

[4] Devchand PR, Keller H, Peters JM, Vazquez M, Gonzalez FJ, Wahli W. The PPAR $\alpha$-leukotriene B4 pathway to inflammation control. Nature. 1996;384(6604):39-43.

[5] Cuzzocrea S, Di Paola R, Mazzon E, et al. Role of endogenous and exogenous ligands for the peroxisome proliferators activated receptors alpha (PPAR- $\alpha$ ) in the development of inflammatory bowel disease in mice. Laboratory Investigation. 2004;84(12):1643-1654.

[6] Cuzzocrea S, Wayman NS, Mazzon E, et al. The cyclopentenone prostaglandin 15 -deoxy- $\Delta^{12,14}$-prostaglandin $\mathrm{J}_{2}$ attenuates the development of acute and chronic inflammation. Molecular Pharmacology. 2002;61(5):997-1007.

[7] Mangelsdorf DJ, Evans RM. The RXR heterodimers and orphan receptors. Cell. 1995;83(6):841-850.

[8] Mukherjee R, Strasser J, Jow L, Hoener P, Paterniti JR Jr, Heyman RA. RXR agonists activate PPAR $\alpha$-inducible genes, lower triglycerides, and raise HDL levels in vivo. Arteriosclerosis, Thrombosis, and Vascular Biology. 1998;18(2):272-276.

[9] Wan Y-JY, Cai Y, Lungo W, et al. Peroxisome proliferatoractivated receptor $\alpha$-mediated pathways are altered in hepatocyte-specific retinoid x receptor $\alpha$-deficient mice. Journal of Biological Chemistry. 2000;275(36):28285-28290.

[10] Wan Y-JY, An D, Cai Y, et al. Hepatocyte-specific mutation establishes retinoid $\mathrm{X}$ receptor $\alpha$ as a heterodimeric integrator of multiple physiological processes in the liver. Molecular and Cellular Biology. 2000;20(12):4436-4444.

[11] Moraes LA, Piqueras L, Bishop-Bailey D. Peroxisome proliferator-activated receptors and inflammation. Pharmacology \& Therapeutics. 2006;110(3):371-385.

[12] Hattori Y, Hattori S, Kasai K. Troglitazone upregulates nitric oxide synthesis in vascular smooth muscle cells. Hypertension. 1999;33(4):943-948. 
[13] Camp HS, Li O, Wise SC, et al. Differential activation of peroxisome proliferator-activated receptor- $\gamma$ by troglitazone and rosiglitazone. Diabetes. 2000;49(4):539-547.

[14] De Dios ST, Hannan KM, Dilley RJ, Hill MA, Little PJ. Troglitazone, but not rosiglitazone, inhibits $\mathrm{Na} / \mathrm{H}$ exchange activity and proliferation of macrovascular endothelial cells. Journal of Diabetes and Its Complications. 2001;15(3):120-127.

[15] Cunard R, Ricote M, DiCampli D, et al. Regulation of cytokine expression by ligands of peroxisome proliferator activated receptors. Journal of Immunology. 2002;168(6):2795-2802.

[16] Chawla A, Barak Y, Nagy L, Liao D, Tontonoz P, Evans RM. PPAR- $\gamma$ dependent and independent effects on macrophagegene expression in lipid metabolism and inflammation. $\mathrm{Na}$ ture Medicine. 2001;7(1):48-52. 


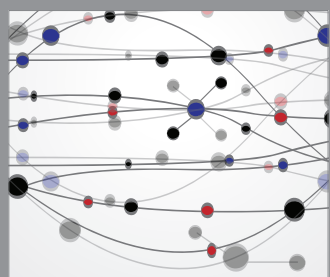

The Scientific World Journal
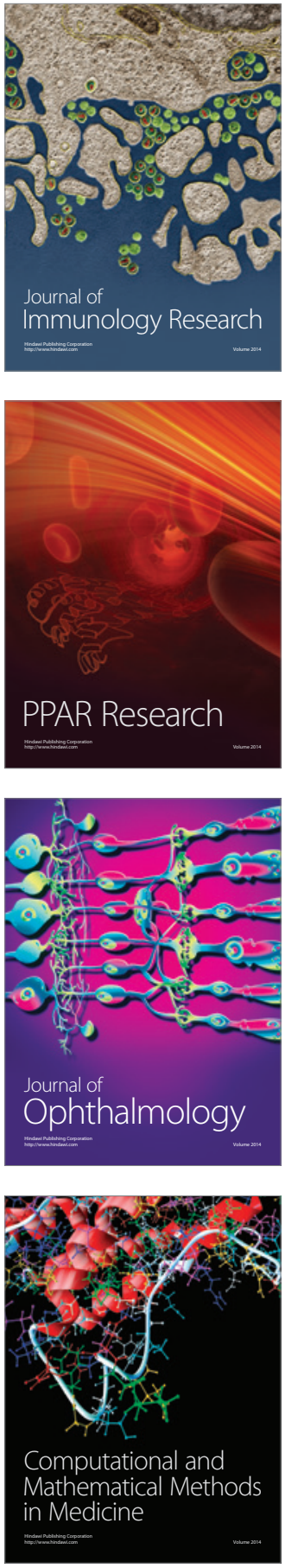

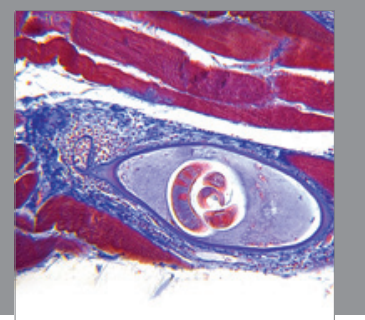

Gastroenterology

Research and Practice
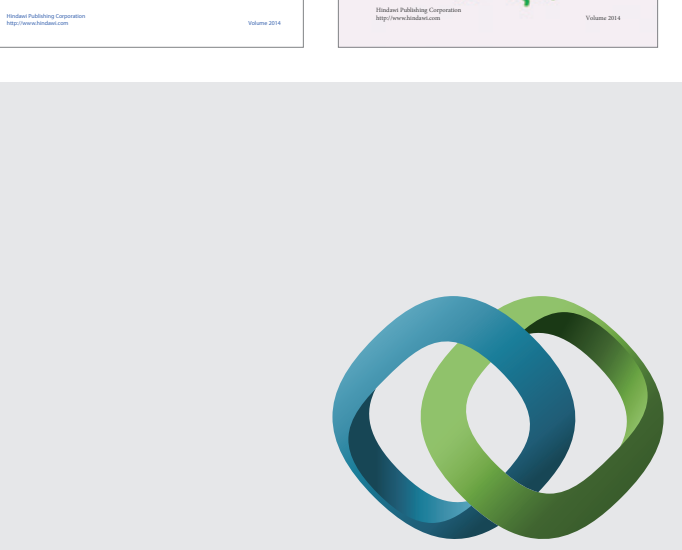

\section{Hindawi}

Submit your manuscripts at

http://www.hindawi.com
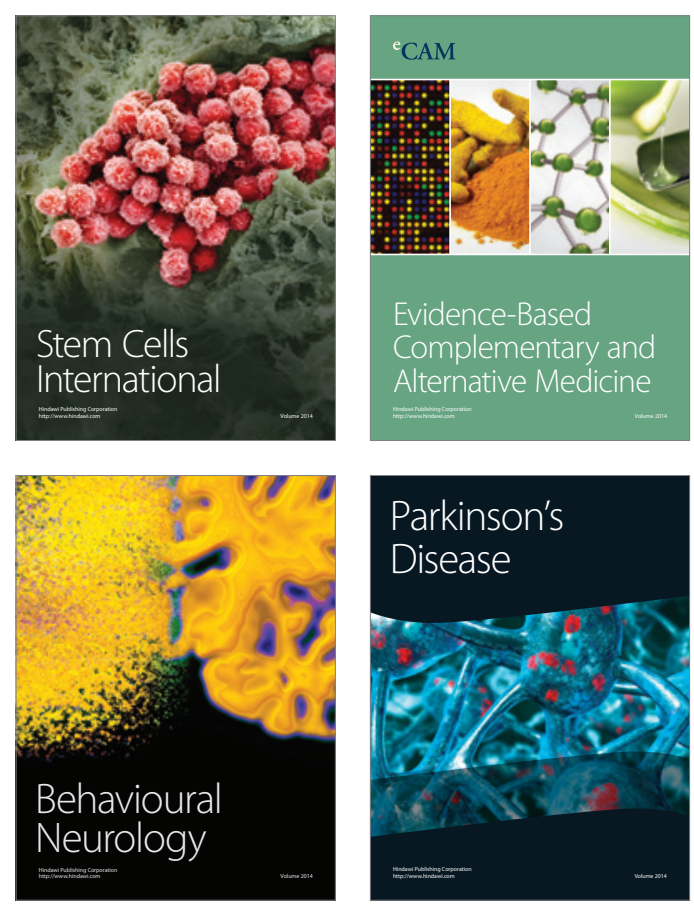

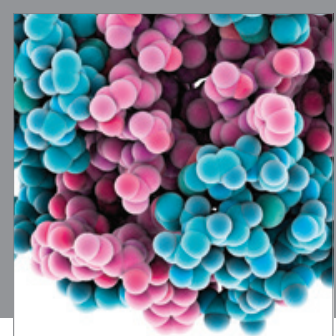

Journal of
Diabetes Research

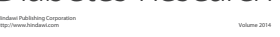

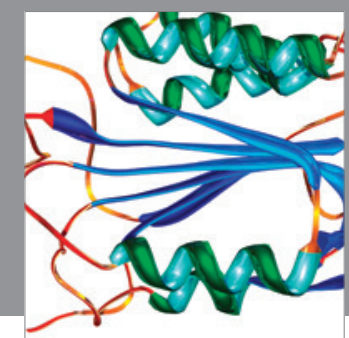

Disease Markers
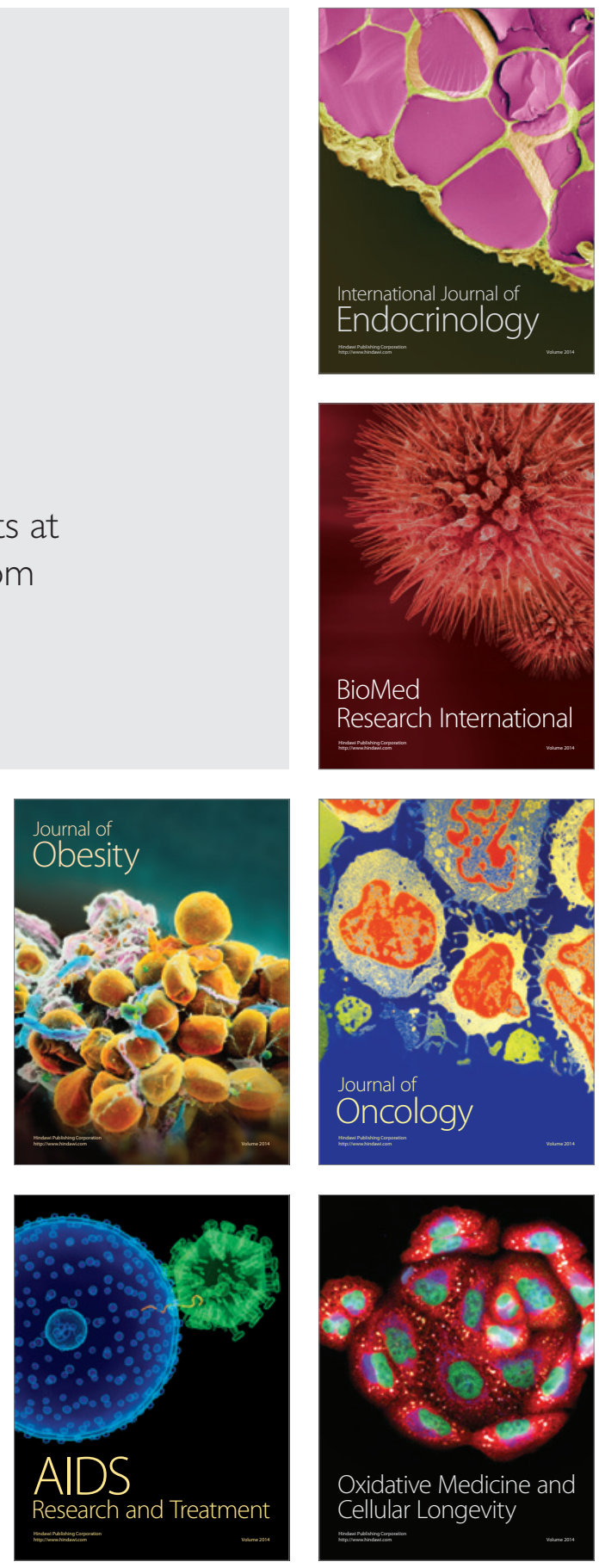